\title{
MUDANÇAS NO TRABALHO E NA VIDA DE BANCÁRIOS PORTADORES DE LESÕES POR ESFORÇOS REPETITIVOS: LER ${ }^{1}$
}

\author{
Neide Tiemi Murofuse ${ }^{2}$ \\ Maria Helena Palucci Marziale ${ }^{3}$
}

\begin{abstract}
Murofuse NT, Marziale MHP. Mudanças no trabalho e na vida de bancários portadores de lesões por esforços repetitivos: LER. Rev Latino-am Enfermagem 2001 julho; 9(4):19-25.

A LER constitui-se num dos graves problemas de saúde dos trabalhadores na atualidade. Com o objetivo de analisar as principais mudanças no trabalho e na vida dos portadores de LER de membros de uma Associação de Portadores de LER de Cascavel-PR, foi desenvolvido o estudo, de natureza qualitativa. Foram realizadas entrevistas semi-estruturadas, com nove bancários. Os primeiros sintomas surgiram no período coincidente com a automação e a introdução de novas tecnologias no sistema financeiro brasileiro e as mudanças na organização do trabalho. Aumento do volume de trabalho e da digitação, horas-extra, ausências de pausas, monotonia, repetitividade, ritmo intenso e controle da produtividade e tensão constituíram os principais elementos. O agravamento das lesões afetou a capacidade produtiva e implicou na dependência para execução de atividades no trabalho e fora dele. $O$ desafio está em garantir os direitos desses trabalhadores.
\end{abstract}

PALAVRAS CHAVE: LER, doença, trabalho, banco, tecnologia, automação

\section{CHANGES IN THE WORK AND LIFE OF BANK EMPLOYEES WITH REPETITIVE STRAIN INJURY: RSI}

Nowadays, Repetitive Strain Injury (RSI) has been one of the most serious problems concerning workers' health. Aiming at analyzing the main changes in the work and life of RSI bearers from an RSI Bearers Association in Cascavel - Paraná, we developed this qualitative study. Semi-structured interviews were applied to nine bank employees. The first symptoms had appeared during the period of automation and introduction of new technology in the Brazilian financial system, which was when changes in work organization took place. The main elements in this process were the increase in work load, use of computers, overtime work, absence of intervals, monotony, repetitive actions, intense work and productivity control, pressure and tension. The aggravation of injuries affected productivity and caused dependence to carry out activities at work and out of it. A challenge lies in ensuring these worker's rights.

KEY WORDS: RSI, diseases, labor, bank, technology, automation

\section{CAMBIOS EN EL TRABAJO Y EN LA VIDA DE BANCARIOS PORTADORES DE LESIONES POR ESFUERZOS REPETITIVOS: LER}

Las LER constituyen uno de los grandes problemas de salud de los trabajadores en la actualidad. Con el objetivo de analizar los principales cambios en el trabajo y en la vida de los portadores de LER de los miembros de una Asociación de Portadores de LER de la ciudad de Cascavel-Paraná, fue desarrollado el estudio, de naturaleza cualitativa. Fueron realizadas entrevistas semi-estructuradas, con nueve bancarios. Los primeros síntomas surgieron en el periodo coincidente con la automatización y la introducción de nuevas tecnologías en el sistema financiero brasileño y los cambios en la organización del trabajo. Aumento del volumen de trabajo y de la digitación, horas extras, ausencia de pausas, monotonía, repetición, ritmo intenso y control de la productividad, tensión y presión constituyeron los principales elementos. El agravamiento de las lesiones limitó físicamente afectando la capacidad productiva y tuvo implicaciones en la dependencia para la ejecución de actividades en el trabajo y fuera de él. El desafío está en garantizar los derechos de estos trabajadores.

PALABRAS CLAVES: LER, enfermedad, trabajo, banco, tecnología, automatización

\footnotetext{
${ }^{1}$ Artigo extraído da Dissertação de Metsrado apresentada ao Programa de Pós-Graduação em Enfermagem Fundamental da Escola de Enfermagem de Ribeirão Preto da Universidade de São Paulo; ${ }^{2}$ Doutoranda do Programa de Enfermagem Fundamental, Docente do Departamento de Enfermagem da UNIOESTE, e-mail: neidetm@terra.com.br; ${ }^{3}$ Professor Associado da Escola de Enfermagem de Ribeirão Preto da Universidade de São Paulo, Centro Colaborador da OMS para o desenvolvimento da pesquisa em enfermagem
} 


\section{INTRODUÇÃO}

A partir dos séculos XVIII e XIX, houve a consolidação da sociedade industrial e foram introduzidas mudanças substanciais no ambiente, ferramentas, máquinas e equipamentos, jornada, tipo e forma de organização do trabalho. Essas mudanças produziram impactos sobre a vida e a saúde das pessoas e em especial dos trabalhadores ${ }^{(1)}$.

Assim as transformações introduzidas no mundo do trabalho com o desenvolvimento da informática e da microeletrônica, no século $\mathrm{XX}$, foram acompanhadas de medidas e atitudes que alteraram os procedimentos, instrumentos e relações. 0 mesmo trabalho que possibilitou a promoção do ser humano, tem produzido novos desafios para a área da saúde. Os avanços conquistados e os novos instrumentos de trabalho, ao mesmo tempo em que propiciou várias facilidades e benefícios, trouxe também problemas à saúde do trabalhador. Dentre esses, encontra-se a Lesão por Esforços Repetitivos - LER, que pode ser considerada como "um dos mais graves problemas no campo da saúde do trabalhador neste fim de século"(2).

O surgimento dos primeiros casos documentados da LER remonta ao ano de 1700 , registrados por Ramazzini, que relacionou o desenvolvimento de processos de adoecimento do trabalhador às funções desempenhadas ${ }^{(3)}$. Em 1800, outros estudiosos destacaram como fator comum os movimentos repetitivos e freqüentes de um grupo isolado de músculos, enquanto o resto do corpo permanece horas a fio parado na mesma posição como sendo as causas do que conhecemos como LER ${ }^{(4)}$.

Na atualidade, a LER está situada entre as mais freqüentes doenças do trabalho no mundo industrializado e o número de adoecidos tem aumentado a cada ano, inclusive no Brasil, chegando nos últimos cinco anos a meio milhão de Comunicações de Acidentes de Trabalho(CAT) ao Instituto Nacional de Seguro Social - INSS ${ }^{(5)}$.

A LER é o termo utilizado no Brasil para definir uma síndrome caracterizada pelo desconforto, incapacidade ou dor persistente em articulações, músculos, tendões e outros tecidos moles, com ou sem manifestações físicas ou clínicas ${ }^{(5-6)}$. Entretanto, essa terminologia não é aceita de maneira geral e foi alterada para Distúrbios Osteomusculares Relacionados ao Trabalho-DORT ${ }^{(6)}$. Neste estudo, optou-se por utilizar a terminologia LER, devido a história de luta dos trabalhadores acometidos pela síndrome, na busca de seu reconhecimento como doença relacionada ao trabalho e 0 modo que eles a denominam.

Segundo a Norma Técnica sobre lesões por esforços repetitivos, do Ministério da Previdência Social, a terminologia LER deve ser utilizada para as afecções que podem acometer "tendões, sinóvias, músculos, nervos, fáscias, ligamentos, de maneira isolada ou associadamente, com ou sem degeneração de tecidos, atingindo principalmente, porém não somente, os membros superiores, região escapular e pescoço, de origem ocupacional"(6).

A complexidade da questão reside no fato de a LER não ser uma doença aguda, mas que se desenvolve durante o exercício profissional e o seu quadro sintomatológico progride, às vezes, irregularmente, existindo uma progressão do quadro, quando as condições de trabalho não são alteradas. Desta forma, os sintomas freqüentemente são multiplicados em novos sintomas e sinais, devido à extensão dos agravos a outros grupos musculares.

Embora avanços tenham sido conquistados, permanece 0 desafio para que a LER seja reconhecida como doença relacionada ao trabalho e que o trabalhador acometido receba o tratamento adequado ou mesmo para que medidas efetivas de prevenção sejam tomadas. Mediante tais dificuldades, inquietou-nos a questão: como será que os trabalhadores estão vivendo a sua condição de portador dessa doença?.

\section{OBJETIVOS}

Analisar as principais mudanças no trabalho e na vida de um grupo de trabalhadores do setor bancário do município de Cascavel-PR.

\section{METODOLOGIA}

Trata-se de uma pesquisa do tipo descritiva, com análise qualitativa dos dados, de abordagem histórico-estrutural. Isto resumidamente implica em que para a observação de uma determinada realidade social é preciso considerar que as condições objetivas e subjetivas podem ser captadas através dos conceitos de historicidade e totalidade ${ }^{(7-8)}$.

Delimitamos a população do estudo aos trabalhadores vinculados à Associação dos Portadores de LER (AP-LER), do município de Cascavel-PR. Dentre os quatorze bancários portadores de LER associados, nove participaram da amostra, sujeitos de ambos os sexos que emitiram livre consentimento em participarem da pesquisa. O número de participantes da amostra foi definido, à medida que com o material colhido verificamos a saturação e a repetição dos conteúdos das entrevistas.

A entrevista semi-estruturada foi a técnica utilizada para a coleta de dados. $O$ roteiro das entrevistas continha duas partes, sendo que na primeira foram coletados visando a caracterização dos sujeitos e na segunda parte duas questões centrais: "conte-me sobre a sua vida, antes e depois de tornar-se uma pessoa portadora de LER" e 
"você poderia descrever como era executado o trabalho na época em que surgiram os sintomas".

$\mathrm{Na}$ elaboração e desenvolvimento da pesquisa foram observados os aspectos éticos constantes na Resolução 196/96, Diretrizes e Normas Regulamentadoras de Pesquisa envolvendo seres humanos ${ }^{(9)}$ e o projeto obteve a aprovação do Comitê de Ética em Pesquisa da Escola de Enfermagem de Ribeirão Preto.

Após a coleta os dados foram ordenados e classificados ${ }^{(10-}$ ${ }^{11)}$, onde 0 agrupamento foi feito por similaridade temática e construídas categorias denominadas "Condições de Trabalho dos bancários" e "A LER como doença do trabalho". Na primeira categoria foi analisado o contexto de trabalho dentro de um sistema financeiro, considerando as atividades desenvolvidas nas funções ocupadas ao longo da carreira profissional como bancários e as mudanças tecnológicas e inovações introduzidas nas empresas bancária e conseqüentemente no processo de trabalho. Foi contemplado nessa análise a auto-descrição dos sujeitos com relação aos seus desempenhos e pretensões profissionais.

$\mathrm{Na}$ segunda categoria denominada "A LER como doença do trabalho" a discussão girou em torno da vivência dos trabalhadores sobre a evolução da LER. Foram analisadas a convivência dos sujeitos com a doença, as patologias associadas, a evolução dos sinais e sintomas. As medidas diagnósticas e terapêuticas prescritas, os afastamentos, as perícias médicas realizadas e o retorno ao trabalho e as mudanças operadas no âmbito do trabalho e na vida social e pessoal do bancário também estiveram presentes na análise dessa categoria.

\section{RESULTADOS E DISCUSSÃO}

Os sujeitos da amostra estudada apresentaram a seguinte caracterização: a maioria era pertencente ao sexo feminino (7), idade compreendida entre 31 a 42 anos (9), tempo de atuação na empresa compreendido entre 12 a 18 anos (9) e atuantes na função de "caixa" (6).

Os dados apresentados corroboram com o perfil dos bancários no Brasil, uma vez que com a automação e a informática determinaram mudanças, principalmente na função de caixa, em que a presença feminina teve um aumento significativo.

Com o desenvolvimento complexo do capitalismo monopolista, o sistema financeiro entra em um acelerado processo de expansão e, conseqüentemente, a força de trabalho bancário adquire crescente importância na economia mundial ${ }^{(12)}$. As lutas femininas das décadas de 60 e 70 e a multiplicação dos postos de trabalho relacionada às operações simplificadas e repetitivas devido a demanda criada pelos sistemas informatizados resultaram na maior contratação da mão-de-obra feminina nos bancos. Assim é que as mulheres passaram a constituir a mão-de-obra que supriria o aumento de serviços surgidos após 1964, tendo o seu número, no setor bancário, aumentado progressivamente, até que em 1988, representavam $40 \%$ dos trabalhadores em estabelecimento bancário, em âmbito nacional. Na década de 90 , as mulheres representam $70 \%$ dos trabalhadores bancários nos Estados Unidos e Canadá. Esse processo também é verificado no Brasil, havendo indicação de que $47 \%$ de mulheres estavam trabalhando em bancos estatais, na década de $1990^{(13)}$.

A totalidade dos entrevistados trabalhava em empresas bancárias desde a década de 1980, tendo entre 12 a 18 anos de tempo de serviço. Assim, eles viveram e acompanharam o processo de automação com as mudanças tecnológicas implantadas no sistema financeiro nacional ${ }^{(14)}$, principalmente as referentes ao segundo momento de automação com a criação dos Centros de Processamentos de Dados-CPDs*.

Os bancos incorporaram uma infra-estrutura de tecnologia, principalmente a partir de 1989, quando o governo brasileiro inicia a abertura da economia do país para as mercadorias estrangeiras, 0 que possibilitou aos grandes bancos a aquisição de novas tecnologias, fazendo deste setor um dos mais avançados do Brasil ${ }^{(14)}$. As mudanças de equipamentos foram vivenciadas pelos entrevistados: fui caixa com máquinas antes da informatização, que é a máquina elétrica (...) autenticador eletrônico e depois (...) o computador, com menos recurso. (...) esse último que agora é IBM que é o mais, com bastante recurso(...) (E1).

Essas inovações tecnológicas acarretaram mudanças no processo de trabalho dos bancários, uma vez que antes da informatização os caixas trabalhavam com máquinas que armazenavam os dados digitados que precisavam ser transmitidos após o fechamento das agências. A partir do recurso da informática, cada caixa passou a operar com um terminal de computador, agilizando o tempo de atualização dos dados. Com a introdução do sistema on line, o terminal de computador possibilitou maior velocidade no atendimento, trazendo com isso a intensificação do ritmo de trabalho e aumento da produtividade ${ }^{(12)}$.

A automação significou, para as instituições bancárias, a possibilidade de agilização das informações e aumento da qualidade e velocidade do processo decisório para os trabalhadores, constatamos através dos trabalhadores da amostra estudada que 0 impacto foi diferente.

Conforme os depoimentos analisados, com a automação

* Local em que eram centralizados todos os dados da movimentação realizada pelas agências durante o dia, em que eram preparados e conferidos documentos, realizadas as entradas de dados no sistema, através de operações simplificadas e repetitivas 
bancária, o caixa foi transformado em digitador, em função de que as atividades anteriormente executados pelos CPDs foram transferidos para eles. Com a introdução de computadores no caixa, o volume de trabalho aumentou em função do número de operações necessárias para a entrada dos dados na realização das atividades de recebimento ou pagamento dos clientes. Mesmo contando com equipamento denominado de leitora ótica de códigos de barras, muitas vezes os documentos não eram lidos por essa máquina, fato que segundo os sujeitos da amostra aumentavam ainda mais o trabalho manual. Desta forma, o modo de operação dos caixas foi alterado e eles passaram a executar, tarefas que exigiam muitos movimentos das mãos e muita concentração.

Com a entrada do modo de produção capitalista na era da globalização, marcada pela intensidade e generalização da internacionalização do capital, os bancos tradicionais encontraram novos concorrentes e os impactos no trabalho bancários foram a intensificação do ritmo do trabalho, exigências redobradas de produtividade e de qualidade, o prolongamento da jornada de trabalho com aumento das horas-extras não remuneradas, a redução do quadro de pessoal, a informatização intensa, o rebaixamento salarial, a instauração de um clima geral de insegurança e precariedade do trabalho ${ }^{(15)}$.

A matéria-prima e o produto dos bancários entrevistados estiveram praticamente resumidos em papéis, números e numerários. O volume de trabalho e os movimentos repetitivos executados nas atividades podem ser acompanhados na fala a seguir: (...) eu emitia assim 30 mil documentos, 40 mil (...) tinha que entrar digitar (...) depois redigitar pra conferir (...) e você contava só uma vez (...) era 30 mil documentos, quarenta mil, mas na verdade foram oitenta mil documentos(...) (E8).

Os entrevistados informaram que desenvolveram atividades em diversos setores do banco e através de seus depoimentos verificou-se que o trabalho executado, em qualquer dos setores mencionados, tinha um conteúdo empobrecido e mecânico, com esforço repetitivo, envolvendo a manipulação de documentos, digitação e conferências de cheques e documentos.

Embora tivessem tempo de serviço estabelecido entre 12 a 18 anos e tivessem executado durante esse período diversas atividades manuais onde esforços repetitivos eram realizados, os primeiros sintomas de LER surgiram com a implantação da informatização e automação nas empresas.

Dos entrevistados sete trabalhavam em banco de economia mista com controle estatal e dois em banco privado, a maioria exercia a função de caixa, dado este que corrobora outros estudos já realizados ${ }^{(16-17)}$ indicando que este é o segmento bancário mais afetado pela LER.

A relação entre a lesão apresentada e as posturas adotadas no trabalho são destacadas nos depoimentos: (...) desencadeou o processo foi o fato de eu segurar os papéis na mão, porque minha dor começou na esquerda, segurar em suspenso os papéis pra passar na leitora (...) foi isso que me prejudicou e eu também era muito rápida, eu era boa no negocinho (...) (E7). (...) as dores que eu sinto é exatamente da posição que eu trabalhava (...) ficava (...) com o pescoço virado (...) jogando sobrecarga em cima dessa região (...) dor nos punhos (...) fazia esse movimento com os cheques (...) ficava de pé porque não tinha jeito de ficar sentada naquelas cadeiras horriveis (...) e jogava todo peso em cima, trabalhava com uma máquina pequeninha (...) com um visorsinho desse tamanho que tinha que ficar com o pescoço ali pra poder olhar (...) (E2).

A manipulação de documentos, dinheiros e números, exigem um esforço muscular estático, que gera cansaço e dores que podem evoluir para inflamação nas estruturas músculoesqueléticas ${ }^{(16)}$.

O progressivo aumento da incidência de LER no segmento dos caixas bancários e, também, dos transtornos de coluna vertebral e oculares é resultante da combinação das características "inadequadas do mobiliário e do equipamento; da organização do trabalho, da tensão sob a qual trabalham os caixas e o ritmo acelerado e ininterrupto que lhes é imposto na maior parte do tempo"(17).

As formas produtivas apoiadas na revolução informativa e em inovações organizacionais que tendem a uma violenta racionalização do trabalho procuram reproduzir em novas bases as condições de domínio do capital sobre 0 trabalho ${ }^{(12)}$. Esta situação pode ser constatada através dos depoimentos analisados, quando os bancários fazem referência as mudanças sentidas em função da informatização e da automação bancária ocorrida e vivida durante suas trajetórias profissionais.

A informatização e a implantação de terminal de computador viabilizou 0 acesso as informações sobre os clientes sem a necessidade de deslocamento do seu posto de trabalho. Esta fixação do trabalhador em seu posto contribuiu para o aumento do número de clientes atendidos e é sobre a rotina de atendimento conforme ilustra a fala a seguir: (...) atendia os clientes, gostava daquilo mas era uma rotina chata, e é claro que se eu pudesse escolher entre um outro serviço e o caixa, eu ia escolher um outro serviço, porque eu acho que outro serviço é bem menos rotineiro, é coisa assim que você aprende mais (...) (E2).

Assim, para atender a nova demanda, os entrevistados procuravam intensificar o trabalho para alcançar a produtividade esperada. As pressões sofridas com as filas, o medo, os colegas de trabalho e da gerência o controle sobre o ritmo e a produtividade era exercido pelo gerente, através dos registros das autenticações realizadas por cada caixa, foram presentes nos depoimentos. (...) a estatistica de autenticação pra ver qual funcionário fazia mais, qual fazia menos, como forma de pressionar (...) a desempenhar uma atividade cada vez mais rápida (...) intensa, saber aquele que faz corpo mole (...) fazia parte 
do arsenal de documentos da agência (...) pra avaliar o funcionário (...) pra poder de alguma outra forma exigir mais (...) (E1).

Os depoimentos revelam que havia problemas de relacionamento interpessoal entre os colegas, havendo uma avaliação velada de "competência" feita pelos próprios colegas de trabalho a partir dos relatórios diários emitidos.

Em função da internalização da estrutura patogênica da organização, o bancário acaba submetendo-se a um ritmo mais intenso de trabalho, colocando em risco sua integridade física e psicológica ${ }^{(17)}$. A exigência da hora-extra era ditada pelo volume de trabalho que variava ao longo do mês e também pela insuficiência do número de funcionários em relação à demanda e a característica do trabalho bancário (as tarefas começam e terminam no mesmo expediente). (...) falta de funcionários então era suprimida pela (...) disposição da gente em resolver o problema do banco, resolver a falta de funcionários através de um trabalho, de um maior empenho (...) (E1).

Neste sentido, os entrevistados não realizavam pausas, reduziam os intervalos de almoço ou lanches e evitavam até parar o trabalho para ir ao banheiro.

Através dos depoimentos foi constatado que eram utilizados equipamentos e mobiliários inadequados ou danificados e que apesar das reclamações registradas com os superiores hierárquicos, os problemas não eram solucionados e que os bancos não acatavam as recomendações legais ${ }^{(18)}$ referente a necessidade de adequação de equipamentos, instrumentos e mobiliários às características psicofisiológicas dos trabalhadores.

A disposição, dedicação, responsabilidade, a satisfação e o reconhecimento profissional, renúncia aos projetos pessoais em favor das necessidades da empresa, foram também elementos comuns encontrados na auto-descrição dos bancários entrevistados. Entretanto, com as dificuldades no diagnóstico médico da lesão e na ineficácia das medidas terapêuticas adotas, houve o agravamento do quadro sintomatológico apresentado pelos entrevistados, o que acabou interferindo e alterando o ritmo e a produtividade no trabalho, causando-lhes sofrimentos físico e mental.

A dificuldade de manter a mesma produtividade aliada às dificuldades vividas, decorrentes da própria doença, provocou mudanças no modo de agir e reagir, dos entrevistados. Apreendemos dos depoimentos que as mudanças ocasionadas em decorrência da LER não foram apenas no aspecto físico, mas causou também abalo na estrutura emocional das pessoas.

Entre os entrevistados verificou-se que a LER provocou mudanças significativas que afetaram os diversos aspectos da vida. Angústias e preocupações, principalmente pela piora do quadro clínico foram constantemente vivenciadas. A limitação física chegou a impedir a execução de atividades rotineiras, de cuidados pessoais e domésticos. Assim, passaram a depender de outras pessoas pela incapacidade de alimentar-se, higienizar-se e vestir-se. (...) passei a não conseguir trocar a roupa (...) segurar os garfos pra me alimentar (...) fiquei totalmente dependente (...) não conseguia me vestir (...) arrumar minha cama, me dar banho, secar meu cabelo, tudo (...) ou era ela ou era meu marido nessa época (...) (E6).

Houve alteração nos hábitos de prática de exercícios físicos dos entrevistados, tais como: natação, caminhadas e futebol. A dificuldade de locomoção seja a pé, de carro ou de transporte coletivo, interferiu na autonomia para o desenvolvimento das atividades de lazer, de trabalho ou mesmo aquelas atividades requeridas ao cumprimento do próprio tratamento de saúde. Além da ineficácia do tratamento, tiveram ainda que conviver com a desconfiança de colegas e chefes e, até mesmo, dos familiares pela incompreensão sobre as dificuldades causadas pela mesma. As mudanças decorrentes da doença interferiam no sistema familiar pela alteração no papel desempenhado dentro do grupo familiar.

A condição de portador de LER tornou-se também um fator de discriminação do trabalhador, como foi apontado nos depoimentos. As pessoas com LER geralmente não se enquadram no padrão de doente comumente conhecido.

A "invisibilidade" da LER, segundo os sujeitos, contribuiu para que os colegas de trabalho não entendessem a razão dos prolongados períodos de afastamento do trabalho para o tratamento, mas ao contrário julgassem como privilégios. A ampliação da área lesionada também não foi compreendida como agravamento do quadro, mas ao contrário, muitas vezes, aumentava a dúvida sobre a existência real de problema de saúde: (...) o meu braço não deforma (...) só incha, fica duro (...) trava tudo e dói, não tem o que eu fazer, vou ter que amputar o braço pra eles verem que eu tô com uma dor, com problema (...) (E8).

Muitas vezes, os entrevistados, relataram que ouviram dos colegas de trabalho que estavam inventando, fingindo a doença. A falta de compreensão e credibilidade das dificuldades vivenciadas ocorreu também por parte dos familiares, o que fez com que eles se sentissem mais solitários.

Com a aquisição da LER e os problemas vivenciados no trabalho, aliado às mudanças que estão ocorrendo na sociedade, aumento do nível de desemprego e das exigências pela produtividade, a permanência no emprego foi considerada, pelos entrevistados, como sendo algo temporário gerando insegurança e dúvidas sobre 0 seu futuro profissional.

O processo de reelaboração da nova condição de vida, após a LER, foi acontecendo de maneira diferenciada entre os entrevistados. Um dos maiores desejos manifestados foi para que seja encontrada a cura, pois enquanto isso não ocorrer eles expressaram que terão muitas dificuldades, principalmente, decorrentes da falta de autonomia para desenvolver as atividades e pela limitação física imposta pela doença. 
A maioria dos entrevistados apontou que a LER é uma doença relacionada ao trabalho, justificando que as estruturas acometidas correspondem à posição adotada no trabalho. Mas nos depoimentos, outros elementos são apontados como sendo os responsáveis pelo surgimento da doença: mobiliários e equipamentos inadequados, longas jornadas, inexistência de pausas, movimento repetitivo, estresse, tensão, auto-exigência e sobrecarga de trabalho.

\section{CONSIDERAÇÕES FINAIS}

Verificamos que os entrevistados acompanharam as mudanças ocorridas no sistema financeiro, com a introdução de novas tecnologias e a reestruturação administrativa ocorridas no momento da automação bancária no Brasil. A preocupação central, por parte dos bancos, foi realizar investimentos em equipamentos e layout das empresas, visando reduzir os custos e atrair os clientes em função da competitividade do mercado e a expansão dos serviços bancários. $O$ aspecto humano envolvido nas mudanças, foi deixado em segundo plano, pois os aspectos centrais no atual modo de produção são 0 capital e o lucro. Assim, o trabalhador, os meios e os instrumentos de trabalho são subordinados ao atendimento da finalidade estabelecida.

A ampliação do conteúdo das atividades, para o bancário, resultou na intensificação e aceleração do ritmo de trabalho, das operações executadas, da atualização dos dados e pela exigência do aumento da produtividade. Assim, ao contrário de liberar o trabalhador das tarefas repetitivas, a automação bancária e o seu processo de informatização, desqualificam-no, substituindo a intervenção inteligente do operador por regulamentos e controles automáticos, que exigem dele somente atenção e precisão de gestos.

Portanto, no atual modo de produção, o trabalho torna-se alheio, estranho, convertendo-se apenas em meio de subsistência do homem. A dicotomia entre o ser que produz e aquele que acumula as riquezas gera o "estranhamento"(19) do produtor em relação a seu trabalho, tendo como conseqüência a não realização do ser social, através de um trabalho compulsório, forçado.

Com a complexificação do processo de trabalho e as novas divisões do trabalho, o homem passou a realizar as atividades em etapas, não conseguindo, muitas vezes, visualizar o seu produto final, devido à fragmentação na produção das mercadorias. No processo de constituição do modo de produção capitalista, os homens são "livres" para tornar-se "proprietários" ou "propriedade". Alguns podem ser proprietários dos meios de produção e comprar a força de trabalho necessária para a produção. Outros, a maioria dos trabalhadores, também são vistos como "proprietários", porém o que eles detêm é a posse de sua força de trabalho, que precisa ser vendida em troca de um salário para garantir a sua sobrevivência ${ }^{(20)}$.
Desta maneira, mesmo produzindo intencionalmente sua sobrevivência, o homem - não sendo proprietário dos meios de produção, portanto não podendo controlar as condições em que produz e os produtos de seu trabalho - sujeita-se à alienação. Essa alienação, provocada pelas relações de trabalho estabelecidas, faz do homem uma das mercadorias que pode ser comercializada com a finalidade de produzir bens e riquezas que são concentradas nas mãos de proprietários.

Abstraímos dos relatos que a LER constitui-se, sobretudo, em desafio aos conceitos clássicos da medicina, pois demonstram que são necessários outros "olhares" para se apreender os nexos entre processo de trabalho e saúde. Além disso, ela necessita de um protocolo de tratamento diferente do até então adotado, pois apenas o enfoque no corpo biológico do indivíduo não tem apresentado resolutividade.

Também se torna desafio aos conceitos clássicos da medicina ocupacional, no que se refere às formas de definir e representar doenças, riscos e os acidentes de trabalho, bem como aos modelos de intervenção. As doenças, sob o ponto de vista dos trabalhadores, revelam que elas não se esgotam nos tradicionais riscos ocupacionais presentes nos ambientes, pois o local de trabalho não se apresenta apenas como meio-ambiente, em que os agentes agressivos estão em equilíbrio ou disfunção com o corpo do trabalhador, percebido como a dissociação das suas determinações históricas e sociais. Mas, muito mais do que isso, o local de trabalho configura-se como território concreto de relações sociais. Assim, é preciso reconhecer que o local de trabalho não é apenas o local em que se realizam os objetivos da valorização e acumulação na dimensão econômica. Ele constitui-se como lugar privilegiado, onde o capital e 0 trabalho se encontram e materializam uma dada correlação de forças nas dimensões políticas e ideológicas.

Em função do aumento crescente do número de casos de LER, algumas agências bancárias têm adotado medidas que visam auxiliar o trabalhador para que ele possa resistir por mais tempo no trabalho, tais como: ginásticas laborais, rodízios de funções e utilização de equipamentos e mobiliários ergonomicamente planejados.

Assim, apesar dos avanços já conquistados no estudo da LER, consideramos que a realização de estudos interdisciplinares são necessários para melhorar a compreensão sobre a gênese da doença, uma vez que entre as décadas de 60 e 70, os trabalhadores mais atingidos eram os de montadoras e grandes indústrias, na década de 70 , as vítimas passaram a ser os digitadores, programadores e analistas de sistema, na década de 80 , os maiores afetados foram os trabalhadores de bancos e atualmente vários outros profissionais também tem sido afetados entre eles; médicos, dentistas, músicos e jornalistas. 


\section{REFERÊNCIAS BIBLIOGRÁFICAS}

1. Bisso EM. O que é segurança do trabalho. São Paulo (SP): Brasiliense;1990.

2. Lima FPA, Araújo JNG, Lima MEA. LER dimensões ergonômicas e psicossociais. Belo Horizonte (MG): Health; 1998.

3. Rio RP. LER ciência e lei: novos horizontes da saúde e do trabalho. Belo Horizonte (MG): Health; 1998. p.89-101.

4. LER: campanha alerta para riscos. Gazeta do Paraná. CascavelPR, 22 out. 1999.

5. Rio RP. LER ciência e lei: novos horizontes da saúde e do trabalho. Belo Horizonte (MG): Health; 1998.

6. Ministério da Previdência Social (BR). Atualização da Norma Técnica sobre Distúrbios Osteomusculares Relacionados ao Trabalho-DORT. Brasilia: Diário Oficial; 11 de julho 1997, Seção 3, p. 14231-9.

7. Demo P. Metodologia científica em ciências sociais. $3^{\mathrm{a}}$ ed. São Paulo (SP): Atlas; 1995.

8. Triviños ANS. Introdução à pesquisa em ciências sociais: a pesquisa qualitativa em educação. $4^{\text {a }}$ ed. São Paulo (SP): Atlas; 1995.

9. Ministério da Saúde (BR). Diretrizes e normas regulamentadoras de pesquisas envolvendo seres humanos. Brasília:Ministério da Saúde; 1997.

10. Alves PC, Minayo MCS. Saúde e doença: um olhar antropológico. Rio de Janeiro (RJ): Fiocruz; 1994.
11. Minayo MCS. O desafio do conhecimento: pesquisa qualitativa em saúde. $5^{\text {a }}$ ed. São Paulo (SP): Hucitec/Abrasco; 1998.

12. Segnini L. Mulheres no trabalho bancário. São Paulo (SP): Universidade de São Paulo; 1998.

13. Ely HB. Mudanças tecnológicas nos bancos brasileiros. São Paulo: SESE-SEEB; 1993.

14. Ely HB. As transformações no sistema financeiro brasileiro e a automação nos bancos comerciais. São Paulo: SESE-SEEB; 1992. 15. Brandimiller PA. Movimento repetitivo: a ponta do iceberg. In: CUT. A saúde no trabalho bancário. São Paulo (SP): Bangraf; 1993. p.69-79.

16. Alves PHR. O psicossocial e a LER. In: Oliveira CR, Alves PHR. Manual prático de LER: lesões por esforços repetitivos. $2^{\mathrm{a}}$ ed. Belo Horizonte (MG): Health; 1998. p. 33-51.

17. Lima FPA. A organização da produção e a LER .In: Lima FPA, Araujo JNG, Lima MEA. LER: dimensões ergonômicas e psicossociais. Belo Horizonte (MG): Health; 1998. p. 237-63.

18. Portaria no 3751 Alteração da Norma Regumentadora 17 Ergonomia. Diário Oficial da República Federativa do Brasil. Brasília (DF): 26 nov. 1990. Seção 1, p. 22576-7.

19. Bock AMB, Furtado O, Teixeira MLT. Psicologias: uma introdução ao estudo de psicologia. $5^{a}$ ed. São Paulo (SP): Saraiva; 1993.

20. Rubinstein SL. Princípios de psicologia geral. $2^{\mathrm{a}}$ ed. Lisboa: Estampa; 1973. 